\title{
ETHICS IN RESEARCH
}

\section{Disclosure of child murder: A case study of ethical dilemmas in research}

\author{
Yandisa Msimelelo Sikweyiya, Rachel Jewkes
}

Disclosures of unreported incriminating information are rarely documented in research; researchers therefore often do not know how to respond when cases arise. Disclosure may occur when respondents volunteer information, without necessarily being asked, and presents an ethical dilemma. Researchers have to choose between maintaining confidentiality and public protection. Debate on confidentiality in research is ongoing; some advocate for totally preserving confidentiality, ${ }^{1}$ while others argue that certain situations warrant a breach of confidentiality. ${ }^{2}$

Although laws and ethical codes guide how we behave in a research context, they may be insufficient to cover complex situations and may conflict or be hard to interpret. ${ }^{3}$ Breaking confidentiality is a complex issue and needs careful deliberation and sensitive handling. Negative consequences that could result from breach of confidentiality include death (presumably of the participant), expatriation or other severe forms of harm. ${ }^{4}$ Cowburn ${ }^{2}$ suggests three issues to consider before breaching confidentiality with a report to authorities. The first is checking whether the disclosure identifies a specific offender, and a specific victim. If so one should consider the nature of the offence, the identity of the perpetrator, the identity of the victim, and when the offence occurred or is threatened to occur. The decision whether to report is based on the balance of these issues. There is little literature on this area of research, and this body of knowledge needs to be documented.

We explore laws and ethical codes that set out researchers' duty to report disclosures of unreported incriminating information by respondents. Ethical and practical reasons for a decision to report or not to report a disclosure are discussed, and implications for research are highlighted.

\section{Case study}

An event has occurred of which it is difficult to speak and impossible to remain silent.

Edmund Burke, on the impeachment of Warren Hastings, 1788

A survey was undertaken in a large community in South Africa. During a face-to-face questionnaire-based interview, a respondent disclosed to the interviewer that she had poisoned her two children with the intention of killing them. Four months earlier, she had given the children (both less than 5 years old) poison. The youngest died in hospital, while the other survived with medical intervention. What prompted the disclosure is unclear, as there were no items in the questionnaire that asked about child murder. Yet the respondent voluntarily disclosed the information to the interviewer. We understand that this was the first time she had made such a disclosure to anyone. She explained that she was a struggling woman with limited economic and social support. She lived with her extended family, was HIV positive and was on ART, and had been preoccupied with thoughts of her death. She said she had poisoned the children so that they would not remain alive with her family after her death.

The interviewer reported the disclosure to the research project managers, who concluded that it should probably be reported to the South African Police Services (SAPS). This was discussed with the chairperson of the research ethics committee (REC) that had approved the study. He advised the researcher to seek advice from the REC's legal adviser. All parties agreed that it should be reported to the SAPS, and this was done.

Reasons to report the matter to the police services included that the researchers felt this was a very serious case as it involved murder and attempted murder; the surviving child still lived with the mother and could be at risk; South African law requires the reporting of cases of child ill-treatment; and at the time of the disclosure, the research participant intimated that to her knowledge no police case had been opened and there had been no inquest into the death of the child.

Yandisa Sikweyiya is a researcher at the Gender and Health Research Unit, South African Medical Research Council (MRC). $\mathrm{He}$ is a PhD student at the University of the Witwatersrand, and currently a co-investigator in an ethnographic study of ethical issues in gender-based violence research in South Africa.

Rachel Jewkes is director of the MRC Gender and Health Research Unit in Pretoria. She is a public health physician involved in research on various aspects of gender, particularly gender-based violence and its intersection with sexual and reproductive health and HIV. She is secretary of the global Sexual Violence Research Initiative.

\section{Legislative framework providing duty for researchers to report child victimisation}

Section 28 (d) of the Constitution of the Republic of South Africa provides that 'every child has a right to be protected from maltreatment, neglect, abuse or degradation.' Complementing the Constitution, the Children's Amendment $\mathrm{Act}^{6}$ makes it a duty for professionals such as medical practitioners, psychologists, social workers, nurses and others who come into contact with abused children to report child abuse to the relevant child protection organisations or a police official. In a directory of the legal rights of child and adolescent research participants in South Africa, Strode et al. ${ }^{7}$ interpret legal obligations concerning researchers who work with children, including that researchers have an obligation to: (i) respond in a lawful and appropriate manner, including reporting where required; and (ii) intervene and assist or refer children for assistance 
where needed. They should tell parents or guardians of children of their obligations at the outset, as reporting may result in breaches of confidentiality.

The Children's Amendment Act ${ }^{6}$ requires anyone in South Africa to report any suspicion of ill-treatment or injuries inflicted deliberately on children. In section 25 of the Children's Act, ${ }^{8}$ subsections 7 and 9 stipulate that in all matters relating to the care, protection and wellbeing of children, the child's best interests must be the guiding principle. There is a legal duty to report maltreatment of children. ${ }^{6}$ Since no legislation deals specifically with researchers' duty to report child maltreatment, this is established through interpretation of various laws.

\section{Why we should report}

Violence against children is a concerning and pervasive problem worldwide. ${ }^{9}$ Age, developmental stage, physical strength and societal status render children vulnerable to various forms of violence, including physical, sexual and emotional. ${ }^{9}$ Children therefore need special protection to shield them from preventable and deliberate harm. ${ }^{10}$ South African law requires adult citizens to report child abuse to the authorities. While no specific laws obligate researchers, these laws are phrased generally and so as citizens, researchers must comply.

In this case the disclosure of the respondent was sufficiently comprehensive to meet the criteria, as suggested by Cowburn, ${ }^{2}$ for assessing whether a disclosure should be reported to the police. A serious crime had been committed by a known perpetrator against known victims, and a child remained at risk. The researchers therefore decided that reporting this case to the police was legally and ethically correct. Furthermore, the confession made to the fieldworker would be admissible as evidence in court and help to bring about justice for the dead child.

\section{Why we should not report}

Arguments against reporting relate to the social circumstances of the interviewee, whose situation and perceived vulnerability should be explored and understood. ${ }^{10}$

Women in South Africa, as in most African communities, occupy a low position in society, characterised by widespread subordination and control by men. ${ }^{11}$ The same can be assumed for the respondent. She had had a difficult life, had a life-threatening disease, which she had not disclosed to her family, and also had problems at her home. She was therefore highly vulnerable, and may have been psychologically distressed at the time she committed the act. She clearly felt remorse, a punishment in itself, and may not have been an ongoing risk to the remaining child.

Explanations for her disclosure include being overwhelmed by guilt and feeling that uncovering the act would ease her; alternatively she may have wanted some sort of intervention, but not necessarily provided by the criminal justice system. Furthermore, in the consent process, the respondent was promised anonymity and confidentiality of the given information. We can therefore assume that she disclosed in good faith, assuming that her confession would go no further.

The fieldworker to whom the incriminating information was disclosed was on a contract employed for the survey. She lived in a section of the large community some kilometers away from where she conducted the interview. This was her first experience in conducting face-to-face interviews in a gender-based violence study, and the disclosure took place in the early stages (week 2) of data collection.

While fieldworkers are trained for data collection, training does not normally focus on explaining certain types of professional responsibilities of fieldworkers, for example, that in the course of their work, they have a responsibility to report known or suspected cases of child maltreatment, on highlighting aspects of laws obligating reporting of previously unreported incriminating information, or on discussing the risks and implications of this for fieldworkers. The fieldworker may have had an ethical, although not legal, obligation, to try to prevent disclosure, which she did not meet. It seems that she was not prepared for such a disclosure, and it may have been difficult for her to anticipate or even prevent the disclosure as Cowburn describes being able to in his research with convicted sex offenders. ${ }^{2}$

The decision to report the case was not supported by the fieldworker, who feared for retaliation and her safety, risks she had not considered when taking the job. She felt strongly that her fears should be paramount in the decision to report. Her fears were increased by the fact that she had left a copy of the consent form with the woman on which she had signed her name as witness. She had probably told the woman where she lived as an 'off-script' part of ice-breaking at the start of the interview and was potentially traceable. Furthermore, she was afraid of reporting the incident to the police services, fearing being implicated in causing adverse consequences for the respondent. On being told that her responsibility might extend to giving a statement to the police that a disclosure of this nature had been made to her, and naming and describing the respondent, she had misgivings. She felt that it would be clear to the interviewee who had committed the crime that she had reported the matter to the police.

Preserving confidentiality is crucial in research, ${ }^{12,13}$ yet fulfilling this obligation is complex. ${ }^{1}$ Reporting incriminating information about a respondent to authorities could be interpreted as breach of confidentiality by some, including the respondent in question. The Medical Research Council ${ }^{14}$ (book 1) posits that researchers must ensure that participants' information remains confidential. Also, 'failure to safeguard information may render a researcher liable for breach of confidentiality' and 'legal exceptions may be imposed in terms of the law', because, arguably, the respondent and others may feel that the fieldworker had disclosed information given to her in confidence.

In a survey where data collection is continuing, reporting such an incident could have negative effects on the study. Although some could view this act as morally praiseworthy and a correct response, others may develop mistrust towards research.

\section{Discussion}

The American Anthropological Association ${ }^{15}$ asserts that the obligation to preserve the welfare of others should supersede knowledge generation in research and that researchers should make choices that maximise benefits for and minimise harm to the greater society. In reporting the case to the police, we perceive that we acted in accordance with this guidance as well as with South African law. We concur with Hearn et al., ${ }^{16}$ who argue that although there are principle-based approaches to guide research processes, it is imperative that researchers discuss ethical dilemmas ${ }^{17}$ and are prepared to open to scrutiny the assumptions and facts on which the choices or decisions made are based. ${ }^{10}$

In this case, there was a need to strike a balance between safeguarding the participant's privacy and confidentiality and obligations to public safety and protection. While the respondent was young and vulnerable and her mental state may have been unstable at the time she committed the act, she was responsible for her children's care and was still the primary carer of one child. By killing and attempting to kill her children, she committed a very serious offence against the children and society. Because of their vulnerability, 
children are often unable to express their needs or defend their interests; they therefore need special protection from the law and others. ${ }^{18}$ While there can be arguments for not reporting the case to the authorities, and there is a need to preserve confidentiality in research, ${ }^{12,13}$ the law is unambiguous in obligating reporting of child abuse to the authorities.

We further argue that the woman's vulnerability would appropriately be taken into account by social workers in assessing risk to her remaining child and by the courts in passing judgement. Researchers are not trained and equipped to evaluate legal cases, ${ }^{19}$ and like other citizens have a legal duty to protect children from harm, which includes reporting suspected or known child abuse.

While considering the interviewer's fears, the research team argued that by working for a research project she had taken on professional responsibilities that placed her responsibility to the child over her own safety. The research team assessed the risk to her as likely to be small and felt that, as an adult, she was inherently more powerful than the child, whose interests should be prioritised. Unlike a child, she could take precautions and protect herself, as she had agency and autonomy. Furthermore, as a citizen, she had a legal duty to report child abuse. ${ }^{19}$

We believe that reporting the incident to the police services provided justice to the murdered child and protected the remaining child, whose life was potentially endangered. Failure to report such a disclosure to the authorities, as provided by South African law, could amount to a 'criminal offence for which the person [researcher] may be liable to a fine or imprisonment.' ${ }^{19}$

\section{Implications for research}

This case study raises implications for community-based research, especially on sensitive topics.

Interviewer training should include mention of the possibility of disclosures of unreported incriminating information to fieldworkers. It should include discussion of the desirability of warning about the implications of, or preventing, a disclosure when it occurs in an interview, and a general discussion of professionalism and what that entails in research. Fieldworkers must be made aware of laws obligating disclosure of previously unreported incriminating information.

In almost all countries confidentiality is potentially limited and research participants should not be told that it is assured when it may not be. Research participants should be given examples of cases where researchers may be obliged to report disclosure(s) by respondents to authorities. For example, in the initial consent phase it should be mentioned that 'there are laws that compel researchers to report incriminating information, therefore all information you provide will be confidential unless you provide details of serious crimes against identifiable person(s)'. We encourage debate on this question and recommend that this should focus on: (i) whether such a statement would deter respondents from speaking freely and candidly about their experiences; and (ii) whether it would stop respondents from disclosing incriminating information in qualitative face-to-face conversational interviews.

Concerning consent and the signing of consent forms, the fieldworker may have been rendered vulnerable by leaving a signed consent form in the participant's house. We are obliged not to expose fieldworkers to possible recrimination by asking them to sign as witnesses in consent forms. While details of the study principal investigator are usually left in a home, these people generally have more financial resources and are better able to protect themselves. More thought needs to be given to avoidance of exposure of fieldworkers to potential risk at work.

The first author acknowledges the Fogarty International Center, National Institutes of Health, for the training he received on ethics through the South African Research Ethics Training Initiative. We wish to acknowledge Mzikazi Nduna, whose critical reflections helped strengthen this paper.

1. Rogers WA. Pressures on confidentiality. www.thelancet.com 2006; 367.

2. Cowburn M. Confidentiality and public protection: Ethical dilemmas in qualitative research with adult male sex offenders. Journal of Sexual Aggression 2005;11(1):49-63.

3. Emanuel EJ, Crouch RA, Arras JD, Moreno JD, Grady C, eds. Ethical and Regulatory Aspects of Clinical Research: Readings and Commentaries. Baltimore, Md: Johns Hopkins University Press, 2004.

4. Beyrer C, Kass NE. Human rights, politics, and reviews of research ethics. Lancet 2002;360:246-251.

5. Republic of South Africa. Statutes of the Republic of South Africa - Constitutional Law. Constitution of the Republic of South Africa, No. 108 of 1996.

Republic of South Africa. Children's Amendment Act. Act No. 41 of 2007.

7. Strode A, Slack C, Grant C, Bamjee S, Mushariwa M. A Directory of the Legal Rights of Child and Strode A, Slack C, Grant C, Bamjee S, Mushariwa M. A Directory of the Legal Rights of Child and
Adolescent Research Participation in South Africa. HIV/AIDS Vaccines Ethics Group, University of KwaZulu-Natal, 2009.

Republic of South Africa. Children's Act, 2005. Act No. 38 of 2005.

Republic of South Africa. Children's Act, 2005. Act No. 38 of 2005.
World Health Organization. World Report on Violence and Health: Summary. Geneva: WHO, 2002.

9. World Health Organization. World Report on Violence and Health: Summary. Geneva: WHO, 2002. Council for International Organisations of Medical Sciences (CIOMS). Intern
for Biomedical Research involving Human Subjects. Geneva: CIOMS, 2002.

11. Seedat M, Van Niekerk A, Suffla S, Ratele K. Violence and injuries in South Africa: prioritising and agenda for prevention. Lancet 2009;374:1011-1022.

2. Wolfers I, Fernandes I. Confidentiality in research. Migration and AIDS. Lancet 1995;346:1303.

13. Schenk K, Williamson J. Ethical Approaches to Gathering Information from Children and Adolescents in International Settings: Guidelines and Resources. Washington, DC: Population Council, 2005.

14. Medical Research Council. Guidelines on ethics or medical research: General principles, 2001. http:// www.sahealthinfo.org/ethics/ethicsbookl.pdf (accessed 5 August 2010).

15. Code of Ethics of the American Anthropological Association. American Anthropological Association, 1998. www.aaanet.org/committees/ethics/ethcode.htm (accessed 11 July 2010).

16. Hearn $\mathrm{J}$ Anderson $\mathrm{K}$ C Cowburn M. Background paper on guidelines for researchers on doing research with perpetrators of sexual violence. Pretoria: Sexual Violence Research Initiative, 2007.

with perpetrators of sexual violence. Pretoria: Sexual Violence Research Initiative, 2007.
Mkhize N. Dialogic ethics: Reconstructing the wisdom of Anansi the spider. Presented at the African Mkhize N. Dialogic ethics: Reconstructing the wisdom of Anansi the spi
Heath Research Ethics Symposium, 11-13 October 2006, Dakar, Senegal.

18. Hull D. Guidelines for the ethical conduct of medical research involving children. Royal College of Hull D. Guidelines for the ethical conduct of medical research involving children. Royal College of
Paediatrics, Child Health: Ethics Advisory Committee, and Professor Sir David Hull. Arch Dis Child 2000;82:177-182

9. McQuoid-Mason D. The Children's Amendment Act and the Criminal Law (Sexual Offences and Related Matters) Amendment Act: Duty to report child abuse and sexual offences against children and mentally disabled persons. S Afr Med J 2008;98:929-931. 